\title{
Population-based case-finding to identify subjects with undiagnosed asthma or COPD
}

\author{
Matthew Preteroti ${ }^{1}$, G. Alex Whitmore ${ }^{2}$, Katherine L. Vandemheen ${ }^{1}$, \\ J. Mark FitzGerald ${ }^{3}$, Catherine Lemière ${ }^{4}$, Louis-Philippe Boulet ${ }^{5}$, Erika Penz ${ }^{6}$, \\ Stephen K. Field ${ }^{7}$, Samir Gupta ${ }^{8}$, R. Andrew Mclvor ${ }^{9}$, Irvin Mayers ${ }^{10}$, \\ Paul Hernandez ${ }^{11}$, Diane Lougheed ${ }^{12}$, Martha Ainslie ${ }^{13}$, Christopher Licskai $^{14}$, \\ Tanweer Azher ${ }^{15}$, Ian Fraser ${ }^{16}$, Masoud Mahdavian ${ }^{17}$ and Shawn D. Aaron ${ }^{1}$
}

Affiliations: ${ }^{1}$ The Ottawa Hospital Research Institute, University of Ottawa, Ottawa, ON, Canada. ${ }^{2}$ Desautels Faculty of Management, McGill University, Montreal, QC, Canada. ${ }^{3}$ Dept of Medicine, The University of British Columbia, Vancouver, BC, Canada. ${ }^{4}$ Dept of Medicine, Université de Montreal, Montreal, QC, Canada. ${ }^{5}$ Centre de recherche, Hôpital Laval, Université Laval, Quebec, QC, Canada. ${ }^{6}$ Dept of Medicine, University of Saskatchewan, Saskatoon, SK, Canada. ${ }^{7}$ Cumming School of Medicine, University of Calgary, Calgary, AB, Canada. ${ }^{8}$ Dept of Medicine and the Li Ka Shing Knowledge Institute of St. Michael's Hospital University of Toronto, Toronto, ON, Canada. ${ }^{9}$ Firestone Institute for Respiratory Health, McMaster University, Hamilton, ON, Canada. ${ }^{10}$ Dept of Medicine, University of Alberta, Edmonton, AB, Canada. ${ }^{11}$ Dept of Medicine, Dalhousie University, Halifax, NS, Canada. ${ }^{12}$ Dept of Medicine, Queen's University, Kingston, ON, Canada. ${ }^{13}$ Dept of Medicine, University of Manitoba, Winnipeg, MB, Canada. ${ }^{14}$ Dept of Medicine, University of Western Ontario, London, ON, Canada. ${ }^{15}$ Dept of Medicine, Memorial University, St John's, NL, Canada. ${ }^{16}$ Michael Garron Hospital, Dept of Medicine, University of Toronto, Toronto, ON, Canada. ${ }^{17}$ Royal Victoria Regional Health Centre, Barrie, ON, Canada.

Correspondence: Shawn D. Aaron, The Ottawa Hospital, General Campus, 501 Smyth Road, Ottawa, ON K1H 8L6, Canada. E-mail: saarondohri.ca

@ERSpublications

$20 \%$ of randomly selected individuals who report respiratory symptoms in Canada have undiagnosed airflow obstruction due to asthma or COPD http://bit.ly/2WdXlaH

Cite this article as: Preteroti M, Whitmore GA, Vandemheen KL, et al. Population-based case-finding to identify subjects with undiagnosed asthma or COPD. Eur Respir J 2020; 55: 2000024 [https://doi.org/ 10.1183/13993003.00024-2020].

\begin{abstract}
Background: 5-10\% of adults may have undiagnosed airflow obstruction. The objective of this study was to develop a population-based case-finding strategy to assess the prevalence of undiagnosed airflow obstruction (asthma or COPD) amongst adults with respiratory symptoms in Canada.

Methods: Adults without a previous history of asthma, COPD or lung disease were recruited using random digit-dialling and asked if they had symptoms of dyspnoea, cough, sputum or wheeze within the past 6 months. Those who answered affirmatively completed the Asthma Screening Questionnaire (ASQ), COPDDiagnostic Questionnaire (COPD-DQ) and COPD Assessment Test (CAT). Those with an ASQ score of $\geqslant 6$ or a COPD-DQ score of $\geqslant 20$ underwent pre- and post-bronchodilator spirometry to diagnose asthma or COPD. Results: 12117 individuals were contacted at home and assessed for study eligibility. Of the 1260 eligible individuals, 910 (72\%) enrolled and underwent spirometry. Ultimately, 184 subjects (20\% of those enrolled) had obstructive lung disease (73 asthma and 111 COPD). Individuals found to have undiagnosed asthma or COPD had more severe respiratory symptoms and impaired quality of life compared with those without airflow obstruction. The ASQ, COPD-DQ, and CAT had ROC areas for predicting undiagnosed asthma or COPD of $0.49,0.64$ and 0.56 , respectively. Four descriptive variables (age, BMI, sex and pack-years smoked) produced better receiver operating characteristic $(\mathrm{ROC})$ values than the questionnaires (ROC area $=0.68$ ). Conclusion: $20 \%$ of randomly selected individuals who report respiratory symptoms in Canada have undiagnosed airflow obstruction due to asthma or COPD. Questionnaires could exclude subjects at low risk but lack the ability to accurately find subjects with undiagnosed disease.
\end{abstract}




\section{Introduction}

Within the North American population, $8 \%$ of adults have been diagnosed with asthma and 6\% have been diagnosed with COPD [1-3]. Collectively, these diseases cost North Americans in excess of US\$90 billion in direct and indirect costs every year $[4,5]$. However, physician-diagnosed asthma and COPD represent only a fraction of individuals living with these diseases. Population-based studies suggest that the prevalence of undiagnosed obstructive lung disease (OLD) may be double that of diagnosed disease [6].

A clinical diagnosis of asthma or COPD requires that a patient exhibit respiratory symptoms and have evidence of physiological airflow limitation on spirometry. For asthma there should be evidence of variable airflow obstruction or airway hyperresponsiveness, whereas a diagnosis of COPD requires evidence of persistent post-bronchodilator airflow obstruction [7, 8]. Spirometry is the most important test used to establish a diagnosis; however, studies have demonstrated that spirometry is often not integrated into clinical practice in North American communities [9, 10]. This under-utilisation of spirometry leads to under-diagnosis of individuals living with the disease. Under-diagnosis of asthma and COPD can also occur if individuals living with undiagnosed asthma or COPD fail to seek medical attention for their respiratory symptoms, or if they have limited access to medical care [11-13].

The US Preventive Services Task Force (USPSTF) published a systematic review assessing published evidence on the benefits and risks of screening for COPD among asymptomatic adults [14]. The task force recommended "against screening for COPD in asymptomatic adults" [15]. However, the USPSTF noted that this recommendation applies only to asymptomatic adults. Critical to the assessment is the USPSTF's conclusion that current medical treatments for COPD reduce symptoms and respiratory exacerbations. Thus, even though the USPSTF recommended against screening asymptomatic adults, its report pointed out that this recommendation is not applicable to "at-risk persons who present to clinicians with symptoms." The USPSTF Recommendation Statement also "encourages clinicians [...] to pursue active case-finding for COPD in patients with risk factors, such as exposure to cigarette smoke" or respiratory symptoms [15].

Case-finding studies to identify undiagnosed asthma in the community are relatively sparse relative to studies for COPD. Nevertheless, undiagnosed asthma remains a prevalent and important public health problem. A Danish study of 1149 subjects who reported respiratory symptoms found 493 (43\%) with definite asthma; of these 249 (51\%) were undiagnosed [16]. Studies have also shown impaired quality of life and higher healthcare utilisation in adult individuals with undiagnosed asthma compared to those without asthma [17].

Current task force recommendations require consideration of the differences between screening, (i.e. testing large numbers of apparently healthy people to detect unrecognised disease at an earlier stage) and case-finding (i.e. evaluating subgroups of people at increased risk of having a disease to make a diagnosis earlier than would occur by waiting for them to present with symptoms or signs). A case-finding approach as is used in this study specifically targets those who have symptoms they have not reported, perhaps because they have not been asked.

A systematic review was conducted by the USPSTF to assess the tools used for the identification of undiagnosed COPD [14, 15]. The review determined that the COPD-Diagnostic Questionnaire (COPD-DQ) is the most extensively studied questionnaire (five studies, $\mathrm{n}=3048$ ). The questionnaire score ranges from 0 to 38. At a threshold score of 20 , sensitivity and specificity values are $63.0 \%$ and $70.1 \%$, respectively [18, 19]. Case-finding methodologies for undiagnosed asthma are sparse. The Asthma Screening Questionnaire (ASQ) is a six-item questionnaire that contains questions pertaining to cough, wheeze, shortness of breath and chest tightness provoked by activities such as laughing, physical activity or talking on the phone [18]. The ASQ score range is $0-20$. The sensitivity and specificity of the ASQ at various threshold values has not been studied [20].

The objectives of this study were to develop a population-based case-finding strategy to identify randomly selected community-dwelling individuals with undiagnosed airflow obstruction in order to assess the prevalence of undiagnosed asthma or COPD amongst adults with respiratory symptoms in Canada. Secondary objectives were to assess the ability of the available case-finding questionnaires to accurately identify subjects with undiagnosed disease, and to determine whether a new composite questionnaire could improve predictability. Our study explicitly excluded subjects with a previous history of asthma, COPD or other lung diseases, as the intent was to discover new cases of previously undiagnosed asthma or COPD.

This article has an editorial commentary: https://doi.org/10.1183/13993003.01514-2020

This article has supplementary material available from erj.ersjournals.com

Received: 6 Jan 2020 | Accepted after revision: 8 March 2020 


\section{Methods}

\section{Participant recruitment}

Adults $\geqslant 18$ years of age were recruited in a two-step process from 19 June 2017 to 16 May 2019, using random digit-dialling of land lines and cell phones located within a 90-min radius of the 10 most populous metropolitan areas in Canada. This technique has been previously used to recruit a random sample from the Canadian urban and rural population [21]. A sample initial contact telephone script follows:

"Hello, my name is Amanda and I'm calling from The Ottawa Hospital. We are conducting a research study and you would help us greatly by answering one question only; this will take less than 15 seconds of your time. We are looking to call back individuals who have experienced breathing problems within the past 6 months. Symptoms of potential breathing problems include shortness of breath, wheezing, increased mucus or sputum, or prolonged cough. Is there anyone in your home who is 18 years of age or older and has experienced one or more of these symptoms in the past 6 months?"

Those households who responded affirmatively received a call back from the local study coordinator; the individual within the household who was identified as having respiratory symptoms was verbally consented and screened for study entry over the telephone. Subjects were excluded from participating if they: 1) had a previous physician diagnosis of asthma, COPD, cystic fibrosis, bronchiectasis, pulmonary fibrosis or lung cancer; 2) had a history of use of an inhaled respiratory medication other than as-needed salbutamol or inhaled nasal medications; 3) had contraindications for spirometry, including a history of myocardial infarction, stroke, aortic/cerebral aneurysm, eye surgery or detached retina within the previous 3 months; 4) were unable to provide or refused to provide informed consent; 5) were in the third trimester of pregnancy; or 6 ) were $<18$ years of age. All subjects determined to be eligible completed the ASQ via telephone. Those who were $\geqslant 60$ years old, as well as subjects who were $<60$ years old who scored $<6$ points on the ASQ, were also administered the COPD-DQ. Those who scored $\geqslant 20$ points on the COPD-DQ or $\geqslant 6$ points on the ASQ were invited to visit the study site for spirometry.

\section{Study procedure}

Once they arrived at the study site, subjects signed written informed consent and then all subjects underwent pre- and post-bronchodilator spirometry administered by certified study personnel to confirm the presence of OLD. Asthma was diagnosed in subjects whose forced expiratory volume in $1 \mathrm{~s}\left(\mathrm{FEV}_{1}\right)$ improved by $\geqslant 12 \%$ and $\geqslant 200 \mathrm{~mL}$ following bronchodilator administration with $400 \mu \mathrm{g}$ of salbutamol [7]. $\mathrm{COPD}$ was diagnosed in subjects whose post-bronchodilator $\mathrm{FEV}_{1} /$ forced vital capacity (FVC) ratio remained below the lower 95\% confidence limit of normal (the lower 95\% confidence limit for a healthy normal, adjusted for sex, age and height) [8]. Subjects who met spirometry criteria for both conditions were considered to have COPD with some bronchodilator reversibility and were classified as COPD for the purposes of the present analysis.

The COPD Assessment Test (CAT) was administered to all participants to measure respiratory symptoms. The CAT is a validated questionnaire composed of eight questions about the severity of respiratory symptoms and generates a summed total score ranging from 0 (no impact on daily activities) to 40 (very high impact on daily activities) [22]. A CAT threshold total score of $>10$ points has been associated with symptomatic COPD [23]. We used The St George's Respiratory Questionnaire (SGRQ) to assess quality of life specific to respiratory diseases.

\section{Statistical analysis}

Descriptive measures for subjects classified with or without OLD were summarised using arithmetic means and standard deviations, where applicable. Receiver operating characteristic (ROC) curves for the disease outcomes of asthma, COPD and OLD were computed for each of the ASQ, COPD-DQ and CAT questionnaires using published scoring formulas for these instruments. Areas under their ROC curves (AUC) were also computed using non-parametric procedures. Sensitivity and specificity values for the questionnaires were calculated using recommended diagnostic threshold scores reported in the literature, as cited earlier.

Multivariate stepwise logistic regression was used to find the combination of questions in the ASQ and CAT questionnaires that best predicted an outcome of OLD. The COPD-DQ questionnaire was not used in this analysis because this questionnaire was only administered to a subset of 499 subjects. Four descriptive variables, age, body mass index (BMI), sex and pack-years smoked, were included in the pool of candidate variables. One question from the ASQ was removed from the candidate pool because it was judged to lack clinical face validity: subjects who reported coughing when laughing were found to be less 
likely to have OLD, and this question was thus removed. The stepwise procedure used entry and removal thresholds for p-values of 0.01 and 0.05 , respectively. No variable was forced into the regression model. The set of questions selected by the stepwise logistic regression is referred to here as the eight-item questionnaire. In the first stage, stepwise regression selected the predictor variables from the candidate pool. The second stage involved taking the best predictor variables from the first stage and re-estimating the regression function for the set of selected predictors. Predicted logistic scores and estimated probabilities of disease for the eight-item questionnaire were computed. A ROC curve was generated for the eight-item regression model, as well as sensitivity and specificity values for a selection of cut-points for the predicted probability of OLD.

Each of the eight CAT questions is a $0-5$ rating scale for severity of a COPD symptom. Although the rating scales are implicitly ordinal (progressing from none to very severe), we discovered that the scales have non-monotonic associations with the disease outcome variable. To account for this tendency, a logistic regression function was computed for each symptom by regressing disease outcomes on a subject's rating responses. The predicted logistic score for each subject was then taken as the subject's response measure for the question. The supplementary material (section S.3) provides additional technical detail and illustrations of this re-scoring procedure.

The OLD outcome consists of two clinically distinct component outcomes: asthma or COPD. To investigate the ability of the eight-item questionnaire to predict these component outcomes, multinomial stepwise logistic regression was used to estimate separate predictive functions for the two component outcomes. The predicted probabilities from these separate functions, when added together, give an estimate of the probability of OLD. ROC curves and AUC values for these separate predictive functions are reported.

A cross-validation of the eight-item model was conducted in which random draws of $80 \%$ of the study sample were selected to estimate the model and then the estimated model was used to predict outcomes of the remaining $20 \%$ of subjects who were withheld. The predictive check was repeated with 1000 random draws. The average predictive performance as measured by sensitivity and specificity was then assessed. All logistic regression models were also tested for goodness of fit using a Hosmer-Lemeshow test.

Statistical analysis was performed using STATA 15 statistical software (StataCorp, College Station, TX, USA). The study was approved by The Ottawa Health Science Network Research Ethics Board as well as the Ethics Boards of the other nine participating study hospitals.

\section{Results}

Figure 1 depicts the results of the case-finding strategy. 12117 individuals were contacted using random digit-dialling and were screened for entry into the study. 10411 were excluded. The most common reasons for exclusion were pre-existing physician-diagnosed COPD or asthma $(n=3936)$. Of the 1706 remaining participants, $446(26 \%)$ subjects were excluded because they did not score $\geqslant 6$ points on the ASQ or $\geqslant 20$ points on the COPD-DQ. Ultimately, 1260 individuals were eligible to undergo spirometry; however, 350 did not attend for spirometry or were unable to complete adequate spirometry. The remaining 910 individuals ( $72 \%$ of those eligible) successfully completed pre- and post-bronchodilator spirometry and were evaluated for a diagnosis of asthma or COPD. Of 910 participants, all but two individuals fully completed the ASQ and CAT questionnaires. According to study protocol, only 499 completed the COPD-DQ questionnaire. Of 910 symptomatic participants, 184 (20\%) subjects had spirometry consistent with a diagnosis of OLD, comprised of $73(8.0 \%)$ cases of asthma and $111(12.2 \%)$ cases of COPD. The COPD cases included 24 who met spirometry criteria for both COPD and asthma.

Table 1 presents the mean summary statistics for the 910 study subjects divided into two groups: those with OLD $(n=184)$ and those without spirometric evidence of OLD $(n=726)$. The group with OLD had a history of heavier smoking; mean total pack years of 31.4 versus $19.8(\mathrm{p}<0.001)$. The mean $\mathrm{FEV}_{1}$ predicted was $75.1 \%$ in the OLD group compared with $95.8 \%$ in the group without OLD $(\mathrm{p}<0.001)$, and the mean pre-bronchodilator $\mathrm{FEV}_{1} / \mathrm{FVC}$ ratio was significantly different between groups $(0.63$ versus $0.77 ; \mathrm{p}<0.001)$. Subjects with OLD had poorer health-related quality of life compared with those without OLD; the mean \pm SD SGRQ total score was $40.5 \pm 18.5$ in the group with OLD versus $37.0 \pm 17.3$ in those without OLD $(\mathrm{p}<0.001)$.

The mean COPD-DQ score in the group with OLD was 23.4 versus 20.8 in the group without OLD $(\mathrm{p}<0.001)$. The mean CAT score in the group with OLD was 18.2 versus 16.7 in the group without OLD $(\mathrm{p}<0.001)$. The mean ASQ score did not differ between groups.

Table 2 shows the sensitivity, specificity and AUC for the ASQ, COPD-DQ and CAT questionnaires when the questionnaires were used to identify the disease for which they were each designed, asthma or COPD 


\section{7}

Individuals were contacted by random

digit-dialling and screened for entry into study

\section{6 excluded
Did not score $\geqslant 6$ points on $A S Q$ or} $\geqslant 20$ points on COPD-DQ

1706 Participants potentially eligible for the study
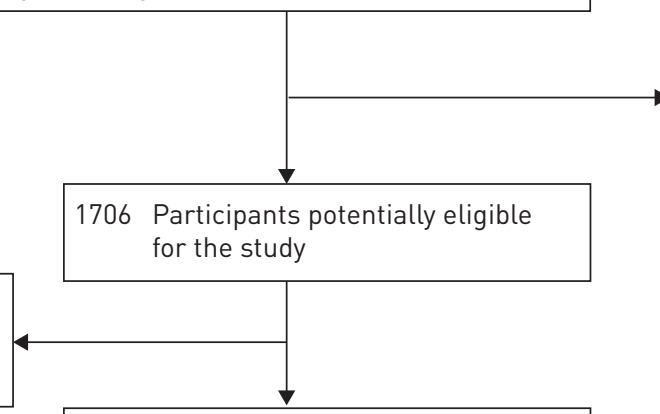

1260 Participants eligible for the study

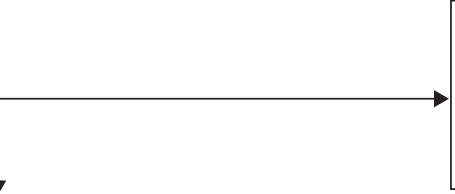

326

\section{0 did not complete spirometry}

Refused to travel to study site for spirometry or did not attend scheduled visit

2 Unable to produce acceptable spirometry results

salbutamol or inhaled nasal medications

273 - History of Mige

Eye surgery or detached retina in past 3 months

2986 No one in home with respiratory symptoms (or cold/URI only)

1211 Refused to answer questions

568 other

910 Completed pre- and post-

bronchodilator spirometry and

could be conclusively evaluated

for a diagnosis of asthma

or COPD

2426 Previous diagnosis of asthma

405 Previous diagnosis of COPD

Previous diagnosis of CF, bronchiectasis, pulmonary fibrosis or lung cancer

Used an inhaled respiratory medication within past 3 months other than p.r.n.

History of MI, heart problems, stroke or aortic or cerebral aneurysm in past 3 months

\begin{tabular}{|c|c|}
\hline \multicolumn{2}{|r|}{$\begin{array}{l}73 \text { diagnosed with asthma } \\
\text { (reversible airflow obstruction) }\end{array}$} \\
\hline 35 & $\begin{array}{l}\text { Mild pre-bronchodilator airflow } \\
\text { obstruction }\left(\mathrm{FEV}_{1} \geqslant 80 \% \text { and }\right. \\
<100 \% \text { ) }\end{array}$ \\
\hline 26 & $\begin{array}{l}\text { Moderate pre-bronchodilator } \\
\text { airflow obstruction (FEV }{ }_{1} \geqslant 50 \% \\
\text { and }<80 \% \text { ) }\end{array}$ \\
\hline 0 & $\begin{array}{l}\text { Severe pre-bronchodilator } \\
\text { airflow obstruction (FEV }<50 \% \text { ) }\end{array}$ \\
\hline 12 & $\begin{array}{l}\text { Pre-bronchodilator } \mathrm{FEV} V_{1} \text { is } \\
\text { within normal range, but there } \\
\text { is a } \geqslant 12 \% \text { and } \geqslant 200 \mathrm{~mL} \\
\text { improvement in } \mathrm{FEV}_{1} \text { and } \\
\text { bronchodilator }\end{array}$ \\
\hline
\end{tabular}

111 diagnosed with COPD

(irreversible airflow obstruction)

38 Mild pre-bronchodilator airflow obstruction $\left(\mathrm{FEV}_{1} \geqslant 80 \%\right.$ and $<100 \%$

61 Moderate pre-bronchodilator airflow obstruction ( $\mathrm{FEV}_{1} \geqslant 50 \%$ and $<80 \%$ )

12 Severe pre-bronchodilator airflow obstruction (FEV $1<50 \%$ )

\section{6 had no airflow \\ obstruction}

FIGURE 1 Results of the case-finding strategy. CF: cystic fibrosis; MI: myocardial infarction; URI: upper respiratory infection; ASQ: Asthma Survey Questionnaire; COPD-DQ: COPD-Diagnostic Questionnaire; $\mathrm{FEV}_{1}$ : forced expiratory volume in $1 \mathrm{~s}$. 


\begin{tabular}{|c|c|c|c|}
\hline & OLD & No OLD & p-value \\
\hline Subjects $\mathrm{n}$ & 184 & 726 & \\
\hline \multicolumn{4}{|l|}{ Characteristics } \\
\hline Age years & $61.3 \pm 14.3$ & $57.1 \pm 15.2$ & $<0.001$ \\
\hline Male sex & $62.3 \%$ & $48.0 \%$ & $<0.001$ \\
\hline $\mathrm{BMI}$ & $29.2 \pm 6.9$ & $30.6 \pm 6.8$ & $<0.001$ \\
\hline \multicolumn{4}{|l|}{ Pre-bronchodilator spirometry } \\
\hline $\mathrm{FEV}_{1} \mathrm{~L}$ & $2.26 \pm 0.77$ & $2.87 \pm 0.81$ & $<0.001$ \\
\hline $\mathrm{FEV}_{1} \%$ pred & $75.1 \pm 15.6$ & $95.8 \pm 15.3$ & $<0.001$ \\
\hline $\mathrm{FEV}_{1} / \mathrm{FVC}$ ratio & $0.63 \pm 0.09$ & $0.77 \pm 0.06$ & $<0.001$ \\
\hline \multicolumn{4}{|l|}{ Post-bronchodilator spirometry } \\
\hline $\mathrm{FEV}_{1} \mathrm{~L}$ & $2.51 \pm 0.83$ & $2.94 \pm 0.83$ & $<0.001$ \\
\hline $\mathrm{FEV}_{1} \%$ pred & $82.8 \pm 17.7$ & $98.0 \pm 16.2$ & $<0.001$ \\
\hline $\mathrm{FEV}_{1} / \mathrm{FVC}$ ratio & $0.66 \pm 0.11$ & $0.79 \pm 0.06$ & $<0.001$ \\
\hline Change in $\mathrm{FEV}_{1}$ post-bronchodilator & $11.6 \pm 10.1 \%$ & $2.9 \pm 4.1 \%$ & $<0.001$ \\
\hline SGRQ total score & $40.5 \pm 18.5$ & $37.0 \pm 17.3$ & $<0.001$ \\
\hline \multicolumn{4}{|l|}{ Diagnostic questionnaires } \\
\hline ASQ score & $8.5 \pm 3.6$ & $8.7 \pm 3.6$ & 0.130 \\
\hline COPD-DQ score ${ }^{\#}$ & $23.4 \pm 5.2$ & $20.8 \pm 5.3$ & $<0.001$ \\
\hline \multicolumn{4}{|l|}{ Symptom assessment } \\
\hline CAT total score & $18.2 \pm 6.9$ & $16.7 \pm 7.0$ & $<0.001$ \\
\hline \multicolumn{4}{|l|}{ Smoking status \% } \\
\hline Lifetime nonsmokers & $24.5 \%$ & $43.4 \%$ & $<0.001$ \\
\hline Previous smokers & $40.8 \%$ & $37.2 \%$ & \\
\hline Current smokers & $34.8 \%$ & $19.4 \%$ & \\
\hline \multicolumn{4}{|l|}{ Smoking history } \\
\hline Total pack-years in previous and current smokers & $31.4 \pm 24.3$ & $19.8 \pm 18.5$ & $<0.001$ \\
\hline
\end{tabular}

Data are presented as mean \pm SD, unless otherwise stated. BMI: body mass index; $\mathrm{FEV}_{1}$ : forced expiratory volume in $1 \mathrm{~s}$; \% pred: \% predicted; FVC: forced vital capacity; SGRQ: St George's Respiratory Questionnaire; ASQ: Asthma Screening Questionnaire; COPD-DQ: COPD-Diagnostic Questionnaire; CAT: COPD Assessment Test. ${ }^{\#}$ : 499 subjects completed this questionnaire (116 with OLD and 383 without OLD).

accordingly, as well as when the questionnaires were used to identify the composite outcome of undiagnosed OLD. The AUCs for identification of undiagnosed OLD were $0.49,0.64$ and 0.56 for the ASQ, COPD-DQ and CAT, respectively. These performance measures for the three questionnaires rely only on their individual questions and do not incorporate any descriptive variables, such as age, BMI, sex or pack-years smoked. When the four descriptive variables (age, BMI, sex and pack-years smoked) were considered alone as predictors, they produced a combined AUC of 0.68 (table 3). The ASQ and four descriptive variables, when considered together, had an AUC of 0.69 for identifying subjects with

TABLE 2 Sensitivity, specificity and areas under the receiver operating characteristic (ROC) curve (AUC) values for the study questionnaire scores using designated thresholds

\begin{tabular}{llcccccc} 
Questionnaire & Disease & Subjects $n$ & Range $^{\#}$ & Threshold $\geqslant$ & Sensitivity $\%$ & Specificity $\%$ & AUC $^{+}$ \\
\hline \multirow{2}{*}{ ASQ } & Asthma & 908 & $0-20$ & 6 & 93 & 16 & 0.53 \\
\multirow{2}{*}{ COPD-DQ } & OLD & 908 & $0-20$ & 6 & 83 & 14 & 0.49 \\
\multirow{2}{*}{ CAT } & COPD & 499 & $0-38$ & 20 & 89 & 34 & 0.71 \\
& OLD & 499 & $0-38$ & 20 & 84 & 34 & 0.64 \\
& COPD & 909 & $0-40$ & 10 & 92 & 15 & 0.58 \\
& OLD & 909 & $0-40$ & 10 & 90 & 16 & 0.56 \\
\hline
\end{tabular}

Values are shown for both the target disease of the questionnaire as well as for the composite outcome of obstructive lung disease (OLD). ASQ: Asthma Screening Questionnaire; COPD-DQ: COPD-Diagnostic Questionnaire; CAT: COPD Assessment Test. \#: minimum and maximum possible scores for the questionnaire. " : derived from $2 \times 2$ contingency tables for the designated thresholds. The values are not adjusted for demographic variables lage, sex, body mass index) or pack-years smoked. + ${ }^{+}$from non-parametric estimates of ROCs for questionnaire scores. 
TABLE 3 Areas under the receiver operating characteristic curve (AUC) for detecting obstructive lung disease measured for: the descriptive variables alone; the individual questionnaires combined with the descriptive variables; and the composite eight-item questionnaire

AUC

$\begin{array}{ll}\text { Descriptive variables }^{\#} & 0.68 \\ \text { Descriptive variables+ASQ } & 0.69 \\ \text { Descriptive variables+COPD-DQ } & 0.68 \\ \text { Descriptive variables+CAT } & 0.69 \\ \text { Eight-item questionnaire } & 0.74\end{array}$

ASQ: Asthma Screening Questionnaire; COPD-DQ: COPD-Diagnostic Questionnaire; CAT: COPD Assessment Test. \#: age, sex, body mass index, pack-years smoked; ": includes descriptive variables.

undiagnosed OLD. The combined COPD-DQ and descriptive variables had an AUC of 0.68 while the combined CAT and descriptive variables had AUC of 0.69 (table 3).

Two-stage stepwise logistic regression was applied to questions found in the ASQ and the CAT, and to the four descriptive variables. The stepwise procedure selected eight questions (table 4). This eight-item questionnaire demonstrated a modest improvement in identifying undiagnosed OLD compared with the individual questionnaires (table 3). The first four items of the eight-item questionnaire include demographic and smoking variables: age, BMI, sex and pack-years smoked. The remaining four items include two questions from the ASQ and two from the CAT (table 4). Responses to the items are weighted by their regression coefficients and summed. The weighted sum represents a logistic score that can be converted mathematically into a probability estimate for OLD. A cut-off of $10 \%$ for this probability gives sensitivity and specificity values of $89 \%$ and $30 \%$, respectively (supplementary table S1). The AUC was 0.74 for the eight-item questionnaire. Supplementary table S2 displays a case demonstration calculating the estimated probability of OLD for a random subject taken from our study population.

Internal cross-validation of the eight-item questionnaire revealed mean sensitivity and specificity pairs of $87 \%$ and $29 \%$, respectively, over 1000 repeated samples. A Hosmer-Lemeshow test showed an acceptable goodness of fit of the logistic regression model for the eight-item questionnaire $(p=0.244)$.

The eight-item questionnaire was evaluated against asthma and COPD disease outcomes independently. The questionnaire demonstrated an AUC of 0.64 for identifying persons with undiagnosed asthma with only one item of the eight-item questionnaire having statistical significance (table 5). The questionnaire performed best at identifying undiagnosed COPD, with an AUC of 0.84, and all eight items in the

TABLE 4 The eight-item questionnaire and associated logistic regression coefficients for detecting undiagnosed obstructive lung disease

\begin{tabular}{|c|c|c|c|}
\hline Question & Possible responses & Coefficient & p-value \\
\hline Age & Number in years & 0.020 & 0.002 \\
\hline Male sex & Yes/no & 0.395 & 0.031 \\
\hline BMI & Number as $\mathrm{kg} \cdot \mathrm{m}^{-2}$ & -0.044 & 0.003 \\
\hline Pack-years smoked & $\begin{array}{l}\text { Number as packs } \cdot \text { day }^{-1} \cdot \text { years } \\
\text { smoked }^{-1}\end{array}$ & 0.024 & 0.000 \\
\hline $\begin{array}{l}\text { Do you experience worsening of wheezing } \\
\text { following physical activity? }\end{array}$ & Yes/no & 0.604 & 0.001 \\
\hline $\begin{array}{l}\text { Do you experience shortness of breath following } \\
\text { physical activity? }\end{array}$ & Yes/no & 0.526 & 0.044 \\
\hline $\begin{array}{l}\text { I have no phlegm in my chest at all - my chest } \\
\text { is completely full of phlegm" }\end{array}$ & $0-5$ & 0.802 & 0.001 \\
\hline $\begin{array}{l}\text { I sleep soundly - I don't sleep soundly because } \\
\text { of my chest condition }\end{array}$ & $0-5$ & 1.045 & 0.023 \\
\hline
\end{tabular}

BMI: body mass index. " : the original 0-5 responses for the phlegm and sleep questions taken from the COPD Assessment Test questionnaire are re-scored before multiplying by the corresponding regression coefficient in the risk calculation. See Section S.3 of the supplementary material for technical explanations. 
TABLE 5 The eight-item questionnaire for detecting undiagnosed asthma

\begin{tabular}{|c|c|c|c|}
\hline Question & Possible responses & Coefficient & p-value \\
\hline Age & Number in years & 0.004 & 0.611 \\
\hline Male sex & Yes/no & 0.284 & 0.263 \\
\hline BMI & Number as $\mathrm{kg} \cdot \mathrm{m}^{-2}$ & -0.007 & 0.697 \\
\hline Pack-years smoked & $\begin{array}{l}\text { Number as packs } \cdot \text { day }^{-1} \cdot \text { years } \\
\text { smoked }^{-1}\end{array}$ & -0.002 & 0.751 \\
\hline $\begin{array}{l}\text { Do you experience worsening of wheezing } \\
\text { following physical activity? }\end{array}$ & Yes/no & 0.335 & 0.202 \\
\hline $\begin{array}{l}\text { Do you experience shortness of breath following } \\
\text { physical activity? }\end{array}$ & Yes/no & 0.419 & 0.236 \\
\hline $\begin{array}{l}\text { I have no phlegm in my chest at all - my chest } \\
\text { is completely full of phlegm } \#\end{array}$ & $0-5$ & 1.042 & 0.003 \\
\hline $\begin{array}{l}\text { I sleep soundly - I don't sleep soundly because } \\
\text { of my chest condition" }\end{array}$ & $0-5$ & 1.014 & 0.122 \\
\hline
\end{tabular}

BMI: body mass index. " : the original 0-5 responses for the phlegm and sleep questions taken from the COPD Assessment Test questionnaire are re-scored before multiplying by the corresponding regression coefficient in the risk calculation. See Section S.3 of the supplementary material for technical explanations.

questionnaire were statistically significant (table 6). The predictive capacity of the eight-item questionnaire is summarised in figure 2 with the AUC increasing from asthma, to OLD, to COPD.

\section{Discussion}

Our case-finding strategy used population-based random sampling to identify symptomatic community-dwelling adults living with undiagnosed OLD. Ultimately, $20 \%$ of the enrolled individuals were confirmed as having undiagnosed airflow obstruction due to asthma or COPD. Thus, an estimated one in five Canadians with respiratory symptoms but without a previous diagnosis of lung disease, were found to have undiagnosed OLD using our population-based case-finding strategy. Persons who had undiagnosed OLD had worse lung function, a heavier smoking history, more severe respiratory symptoms and poorer disease-specific quality of life, compared with those without OLD.

Other approaches to case-finding COPD, but not asthma, are currently being developed [24]. A recently published study used machine-learning methods to select and validate the variables that are most important in identifying patients with clinically significant COPD. The investigators used random forest analysis to reduce 44 identified variables down to a five-item CAPTURE (COPD Assessment in Primary Care to Identify Undiagnosed Respiratory Disease and Exacerbation Risk) questionnaire [25]. Using the CAPTURE questionnaire together with measurement of peak expiratory flow exhibited the best sensitivity

TABLE 6 The eight-item questionnaire for detecting undiagnosed COPD

\begin{tabular}{|c|c|c|c|}
\hline Question & Possible responses & Coefficient & $\mathrm{p}$-value \\
\hline Age & Number in years & 0.037 & 0.000 \\
\hline Male sex & Yes/no & 0.522 & 0.032 \\
\hline BMI & Number as $\mathrm{kg} \cdot \mathrm{m}^{-2}$ & -0.086 & 0.000 \\
\hline Pack-years smoked & $\begin{array}{l}\text { Number as packs } \cdot \text { day }^{-1} \cdot \text { years } \\
\text { smoked }^{-1}\end{array}$ & 0.037 & 0.000 \\
\hline $\begin{array}{l}\text { Do you experience worsening of wheezing } \\
\text { following physical activity? }\end{array}$ & Yes/no & 0.861 & 0.001 \\
\hline $\begin{array}{l}\text { Do you experience shortness of breath following } \\
\text { physical activity? }\end{array}$ & Yes/no & 0.721 & 0.047 \\
\hline $\begin{array}{l}\text { I have no phlegm in my chest at all - my chest } \\
\text { is completely full of phlegm" }\end{array}$ & $0-5$ & 0.833 & 0.002 \\
\hline $\begin{array}{l}\text { I sleep soundly - I don't sleep soundly because } \\
\text { of my chest condition"\# }\end{array}$ & $0-5$ & 1.419 & 0.037 \\
\hline
\end{tabular}

BMI: body mass index. \#: the original 0-5 responses for the phlegm and sleep questions taken from the COPD Assessment Test questionnaire are re-scored before multiplying by the corresponding regression coefficient in the risk calculation. See Section S.3 of the supplementary material for technical explanations. 
FIGURE 2 Receiver operating characteristic curves derived from the eight-item questionnaire for separate predictive equations for asthma, COPD and the combined composite outcome of obstructive lung disease (OLD). The respective area under ROC curve values are 0.74 (OLD), 0.64 (asthma) and 0.84 (COPD).

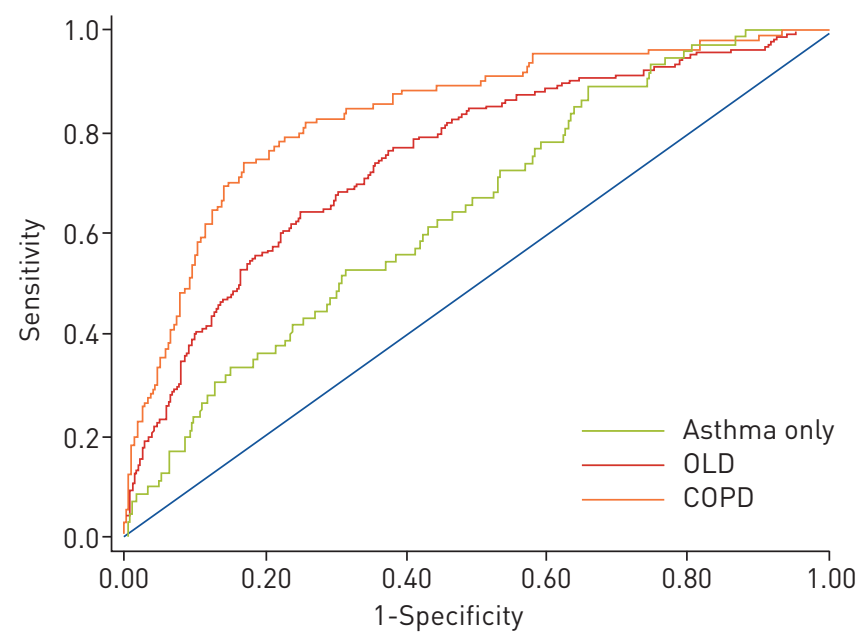

(89.7\%) and specificity (78.1\%) for distinguishing COPD cases from control subjects in a primary care setting. Similar pre-screening questionnaires have been developed in Latin-American countries. The PUMA pre-screening COPD questionnaire includes seven items: sex, age, pack-years smoking, dyspnoea, sputum, cough and whether previous spirometry was performed. In a validation study, the questionnaire had an AUG of 0.73 and showed moderate accuracy for identifying subjects with COPD within a primary care setting [26]. However, both the PUMA and CAPTURE questionnaires do not address case-finding for asthma.

We used pre-existing questionnaires to identify subjects with respiratory symptoms in order to maximise our chances of finding subjects with undiagnosed OLD. The COPD-DQ and ASQ questionnaires were used to exclude subjects at low risk, and ultimately $26 \%$ of potentially eligible subjects were excluded because both their ASQ and COPD-DQ scores fell below published thresholds associated with disease. However, neither of these two questionnaires, nor the CAT questionnaire, demonstrated good performance for case-finding undiagnosed OLD. Moreover, the set of four descriptive variables (age, sex, BMI and pack-years smoked) displayed a standalone ability to identify undiagnosed OLD (AUC 0.68), which was better than the existing questionnaires. Adding the individual questionnaires (the ASQ, COPD-DQ and CAT) to these four descriptive variables had little impact on the predictive value, with respective AUCs of $0.69,0.68$ and 0.69 . The results suggest that most of the predictive strength for identifying OLD comes from these key demographic factors and an individual's smoking history. The screening questionnaires provide little, if any, value.

We acknowledge that the CAT is not validated as a COPD diagnostic tool and is not validated for measuring symptoms in asthmatics, nor is the COPD-DQ validated for use in diagnosing asthma. However, we used these tools in this exploratory study to determine whether we could create a new composite questionnaire that would improve prediction of undiagnosed COPD or asthma. As such, we selected questions from these assessment tools that we found were highly predictive of undiagnosed asthma or COPD, and we incorporated these questions into our eight-item questionnaire.

We used stepwise logistic regression techniques to find the combination of questions in the ASQ and CAT questionnaires that best predicted an outcome of OLD. The resulting eight-item questionnaire displayed a superior ability to predict OLD than the individual existing questionnaires. The AUC for the eight-item questionnaire for identification of OLD was still not impressive (0.74). Furthermore, only one item of the eight-item questionnaire had significant predictive ability for identifying undiagnosed asthma. These results suggest that more research is needed to build effective questionnaires for case-finding undiagnosed OLD, especially asthma, in communities. The challenge will be to find simple questions that can be posed to respondents and answered easily without requirement for lung function testing.

There are some limitations to our study. Our study identified more cases of undiagnosed COPD compared with undiagnosed asthma. This may have occurred because 24 individuals who met spirometry criteria for both conditions were considered to have COPD with some bronchodilator reversibility and were classified as COPD for the purposes of the present analysis, rather than as asthma-COPD overlap. It is possible that some of these subjects could have asthma, rather than COPD, and this might only become evident after treatment with bronchodilators and inhaled steroids fully resolves their airflow obstruction. This could ultimately result in re-classification of some subjects who met spirometry criteria for both conditions. 
It is also possible that our study missed finding asthma in some subjects [19]. We did not employ bronchial challenge testing or exhaled nitric oxide fraction $\left(F_{\mathrm{ENO}}\right)$ testing in those who tested negative for airflow obstruction or bronchodilator reversibility (726 out of 910 participants), since we wanted our case-finding strategy to be potentially translatable to community practices, and within communities bronchial challenge testing is relatively expensive and difficult to access. Therefore, some symptomatic individuals who have asthma with airway hyperresponsiveness, but without reversible airway obstruction, may have been missed. We are currently undertaking a sub-study to try to determine the prevalence of undiagnosed asthma in those subjects in our case-finding study who did not exhibit airflow obstruction or bronchodilator reversibility. Subjects who tested negative for OLD using spirometry are being enrolled and they are undergoing bronchial challenge tests, sputum induction for eosinophils, blood eosinophilia measurements and $F_{\mathrm{ENO}}$ measurements to attempt to discover evidence of undiagnosed asthma. This sub-study is currently ongoing. Finally, individuals with asthma or COPD who were not aware of symptoms (e.g. those who had significant smoking histories and potential airflow obstruction but without symptoms) were not detected using this case-finding strategy.

Another potential limitation of our study is that $>12000$ phone calls had to be made, and 910 subjects tested with spirometry, in order to ultimately find 184 subjects with undiagnosed OLD. The cost of this strategy, while not a focus of the current study, was considerable. Random-digit dialling is probably not a practical or affordable way to find cases of undiagnosed asthma or COPD, although it was the right research approach to ensure selection of a representative population-based sample of subjects with respiratory symptoms for this study, in order to determine the prevalence of undiagnosed airflow obstruction in the population.

The results of our study bring up some important questions outside the scope of the current report, such as "Why are these patients undiagnosed?" and "Are there clinical benefits associated with case-finding and early diagnosis of OLD?" We are in the process of recruiting a control group of subjects with physician-diagnosed asthma or COPD to determine what patient factors and health system factors may predispose these subjects to be less likely to be diagnosed compared to subjects with physician-diagnosed disease. In addition, we are currently undertaking a clinical trial to explore whether case-finding and diagnosing previously undiagnosed OLD has value. Patients who are found to have undiagnosed asthma or COPD are being randomised to an intensive early treatment strategy based on Global Initiative for Asthma (GINA) and Global Initiative for Chronic Obstructive Lung Disease (GOLD) guidelines versus usual care. This clinical trial will allow us to determine whether detection of undiagnosed OLD, with subsequent provision of early intensive treatment, provides clinical benefit.

In summary, our study found that undiagnosed asthma and COPD can be identified in randomly selected adults from the community. Our population-based case-finding strategy found that $\sim 20 \%$ of Canadian adults without a previous history of diagnosed lung disease, who report recent or current respiratory symptoms, have undiagnosed asthma or COPD. Existing symptom questionnaires designed for case-finding subjects were relatively unhelpful and lacked predictive ability to accurately find subjects with undiagnosed asthma or COPD in the community. More research is needed to develop better case-finding tools, especially case-finding tools for the identification of undiagnosed asthma.

Acknowledgements: The authors gratefully acknowledge the invaluable assistance of the following individuals from the study sites. Ottawa Hospital Research Institute, Ottawa, ON: Taylor Poulin, Joanne Cassidy, Vicky Panteleakos, Amanda Bergeron, Susan Deveau, Jennifer Biggs; Vancouver General Hospital, Vancouver, BC: Shelley Abercromby, Jana Caine, David Savage, Natasha Verzosa, Ravneet Mahal; Queen Elizabeth II Health Sciences Centre, Halifax, NS: Scott Fulton; Hôpital du Sacré Coeur de Montréal, Montréal, QC: Simone Chaboillez, Meliza Benabdallah; St. Joseph’s Hamilton, Hamilton, ON: Liz Johnson; St. Boniface Hospital, Winnipeg, MB: Cheryl Noble; Institut Universitaire de Cardiologie et de Pneumologie de Québec-Université Laval, Québec, QC: Johane Lepage, Joanne Milot; University of Calgary, Calgary, AB: Lisette Machado; University of Alberta, Edmonton, AB: Miranda Bowen, Fay Hartt, Angie Hillaby; St. Micheal's Hospital, Toronto, ON: Stephanie Segovia, Carolyn Spiegel-Feld; Queen's University Kingston General Hospital, Kingston, ON: Ann Taite; University of Saskatchewan Royal University Hospital, Saskatoon, SK: Nancy Zacher, Janet Baran; London Health Sciences Centre - Victoria Hospital, London, ON: Katie Maguire, Heba Almadhoun; St. Clare's Mercy Hospital, St John's, NL: Sarah Anthony, Heather Dalton; Royal Victoria Regional Health Centre, Barrie, ON: Ashley Brown; Michael Garron Hospital, Toronto, ON: Liz Lee. Data manager, Ottawa Hospital Research Institute, Ottawa, Ontario: Dong Vo. Random digit-dialling: ASDE Survey Sampler, Inc. (Gatineau, QC, Canada). We would also like to thank the study participants who gave their time and came in for the study visits.

Author contributions: Conception and design: S.D. Aaron and G.A. Whitmore. Analysis and interpretation: M. Preteroti, G.A. Whitmore and S.D. Aaron. Drafting the manuscript for important intellectual content: M. Preteroti, G.A. Whitmore, S.D. Aaron, K.L. Vandemheen, J.M. FitzGerald, C. Lemière, L-P. Boulet, E. Penz, S.K. Field, S. Gupta, R.A. McIvor, I. Mayers, P. Hernandez, D. Lougheed, M. Ainslie, C. Licskai, T. Azher, I. Fraser and M. Mahdavian.

Conflict of interest: M. Preteroti has nothing to disclose. G.A. Whitmore has nothing to disclose. K.L. Vandemheen has nothing to disclose. J.M. FitzGerald has nothing to disclose. C. Lemiere reports grants and personal fees for advisory 
board work, consultancy and lectures from AstraZeneca, grants and personal fees for advisory board work and lectures from TEVA Innovation, personal fees for advisory board work and consultancy from GlaxoSmithKline, personal fees for advisory board work from Sanofi, outside the submitted work. L-P. Boulet reports research grants for participation in multicentre studies from AstraZeneca, Boston Scientific, GlaxoSmithKline, Hoffman La Roche, Novartis, Ono Pharma, Sanofi and Takeda, support for research projects introduced by the investigator from AstraZeneca, Boehringer Ingelheim, GlaxoSmithKline, Merck and Takeda, fees for consulting and advisory boards from AstraZeneca, Novartis and Methapharm, nonprofit grants for production of educational materials from AstraZeneca, Boehringer Ingelheim, GlaxoSmithKline, Merck and Novartis, conference fees from AstraZeneca, GlaxoSmithKline, Merck and Novartis, support for participation in conferences and meetings from Novartis and Takeda. E. Penz reports CIHR funding of UCAP study, during the conduct of the study; grants, personal fees for advisory board work, consultancy and lectures, and non-financial (travel) support from AstraZeneca, personal fees for advisory board work and non-financial (travel) support from GlaxoSmithKline and Boehringer Ingelheim, outside the submitted work. S.K. Field reports grants from GSK, InsMed, Novartis and Boehringer Ingelheim, outside the submitted work. S. Gupta has nothing to disclose. R.A. McIvor has nothing to disclose. I. Mayers has nothing to disclose. P. Hernandez reports grants from CIHR, during the conduct of the study; personal fees for consultancy from Actelion, GlaxoSmithKline, Novartis, Sanofi and Teva, personal fees for consultancy and educational activities from AstraZeneca, grants and personal fees for consultancy and educational activities from Boehringer Ingelheim, grants from Cyclomedica, Grifols and Prometic, outside the submitted work. D. Lougheed reports grants from AstraZeneca, GlaxoSmithKline, Hoffman LaRoche Ltd, Novartis, Government of Ontario's Innovation Fund, Allergen NCE, Janssen, Canadian Institutes of Health Research, Manitoba Workers Compensation Board and Ontario Lung Association/Canada Health Infoway, grants and honoraria for educational activities from Ontario Lung Association, honoraria for educational activities from Canadian Thoracic Society, honoraria for advisory board work from AstraZeneca PRECISION Program, outside the submitted work; and is the nominated Canadian Thoracic Society representative on the Canadian Lung Association's Board of Directors. M. Ainslie has nothing to disclose. C. Licskai reports grants and personal fees from AstraZeneca, Boehringer Ingelheim, Novartis and Pfizer, personal fees from GSK, outside the submitted work. T. Azher has nothing to disclose. I. Fraser has nothing to disclose. M. Madavian reports personal fees for lectures from AstraZeneca, personal fees for lectures and non-financial (drug sample) support from Novartis and Boehringer Ingelheim, non-financial (drug sample) support from GSK, outside the submitted work. S.D. Aaron has nothing to disclose.

Support statement: This work was supported by the Canadian Institutes of Health Research, FDN grant 154322. Funding information for this article has been deposited with the Crossref Funder Registry.

\section{References}

1 Ford ES, Mannino DM, Wheaton AG, et al. Trends in the prevalence of obstructive and restrictive lung function among adults in the United States: findings from the National Health and Nutrition Examination surveys from 1988-1994 to 2007-2010. Chest 2013; 143: 1395-1406.

2 Gershon AS, Warner L, Cascagnette P, et al. Lifetime risk of developing chronic obstructive pulmonary disease: a longitudinal population study. Lancet 2011; 378: 991-996.

3 Turner R, DePietro M, Ding B. Overlap of asthma and chronic obstructive pulmonary disease in patients in the United States: analysis of prevalence, features, and subtypes. JMIR Public Health Surveill 2018; 4: e60.

4 Chronic Obstructive Pulmonary Disease (COPD). Center for Disease Control and Prevention. 2018. https://www. cdc.gov/copd/infographics/copd-costs.html

5 Asthma in the US. Center for Disease Control and Prevention. 2011. https://www.cdc.gov/vitalsigns/asthma/index. html

6 Johnson KM, Bryan S, Ghanbarian S, et al. Characterizing undiagnosed chronic obstructive pulmonary disease: a systematic review and meta-analysis. Respir Res 2018; 19: 26.

7 Global Initiative for Asthma. Global Strategy for Asthma Management and Prevention. 2019. https://ginasthma. org/wp-content/uploads/2019/06/GINA-2019-main-report-June-2019-wms.pdf Date last accessed: August 1, 2019.

8 Global Initiative for Chronic Obstructive Lung Disease (GOLD). Global Strategy for the Diagnosis, Management and Prevention of COPD. 2019. https://goldcopd.org/wp-content/uploads/2018/11/GOLD-2019-v1.7-FINAL14Nov2018-WMS.pdf Date last accessed: August 1, 2019.

9 Gershon AS, Hwee J, Croxford R, et al. Patient and physician factors associated with pulmonary function testing for COPD: a population study. Chest 2014; 145: 272-281.

10 Gershon AS, Victor JC, Guan J, et al. Pulmonary function testing in the diagnosis of asthma: a population study. Chest 2012; 141: 1190-1196.

11 Gershon AS, Hwee J, Chapman KR, et al. Factors associated with undiagnosed and overdiagnosed COPD. Eur Respir J 2016; 48: 561-564.

12 Aaron SD, Boulet LP, Reddel H, et al. Under-diagnosis and over-diagnosis of asthma. Am J Respir Crit Care Med 2018; 198: 1012-1020.

13 Diab N, Gershon A, Sin D, et al. Under-diagnosis and over-diagnosis of chronic obstructive pulmonary disease Am J Respir Crit Care Med 2018; 198: 1130-1139.

14 Guirguis-Blake JM, Senger CA, Webber EM, et al. Screening for chronic obstructive pulmonary disease: evidence report and systematic review for the US Preventive Services Task Force. JAMA 2016; 315: 1378-1393.

15 Preventive Services US. Screening for chronic obstructive pulmonary disease: US Preventive Services Task Force recommendation statement. JAMA 2016; 315: 1372-1377.

16 Backer V, Harmsen L, Lund T, et al. A 3-year longitudinal study of asthma quality of life in undiagnosed and diagnosed asthma patients. Int I Tuberc Lung Dis 2007; 11: 463-469.

17 Adams RJ, Wilson DH, Appleton S, et al. Underdiagnosed asthma in South Australia. Thorax 2003; 58: 846-850.

18 Stanley AJ, Hasan I, Crockett AJ, et al. COPD Diagnostic Questionnaire (CDQ) for selecting at-risk patients for spirometry: a cross-sectional study in Australian general practice. NPJ Prim Care Respir Med 2014; $24: 14024$.

19 Kotz D, Nelemans P, van Schayck CP, et al. External validation of a COPD diagnostic questionnaire. Eur Respir J 2008; 31: 298-303. 
20 Shin B, Cole SL, Park SJ, et al. A new symptom-based questionnaire for predicting the presence of asthma. Invest Allergol Clin Immunol 2010; 20: 27-34.

21 Aaron SD, Vandemheen K, FitzGerald JM, et al. Reevaluation of diagnosis in adults with physician-diagnosed asthma. JAMA 2017; 317: 269-279.

22 Jones PW, Harding G, Berry P, et al. Development and first validation of the COPD Assessment Test. Eur Respir J 2009; 34: 648-654.

23 Tsiligianni IG, Alma HJ, de Jong C, et al. Investigating sensitivity, specificity, and area under the curve of the clinical COPD questionnaire, COPD assessment test, and modified Medical Research Council scale according to GOLD using St George's respiratory questionnaire cutoff 25 (and 20) as reference. Int J Chron Obstruct Pulmon Dis 2016; 11: 1045-1052.

24 Labaki W, Han ML. Improving detection of early chronic obstructive pulmonary disease. Ann Am Thorac Soc 2018; 15: Suppl. 4, S243-S248.

25 Martinez FJ, Mannino D, Leidy NK, et al. A new approach for identifying patients with undiagnosed chronic obstructive pulmonary disease. Am J Respir Crit Care Med 2017; 195: 748-756.

26 Varela M, Montes de Oca M, Wehrmeister F, et al. External validation of the PUMA COPD diagnostic questionnaire in a general practice sample and the PLATINO study population. Int J Chron Obstruct Pulmon Dis 2019; 14: 1901-1911. 